\title{
Critical Discourse Analysis of the Appeals in English Women's Advertisements
}

\author{
Cao Shuo (Corresponding author) \\ School of Foreign Languages, Dalian University of Technology \\ 2\# Linggong Road, Ganjingzi District, Dalian, 116023 \\ Tel: 86-0411-84707346 E-mail: mollycao1977@gmail.com \\ Huili Wang \\ School of Foreign Languages, Dalian University of Technology \\ 2\# Linggong Road, Ganjingzi District, Dalian, 116023 \\ Tel: 86-0411-84707346_E-mail: huilipegasus@gmail.com \\ Yucui Wang \\ School of Foreign Languages, Dalian University of Technology \\ 2\# Linggong Road, Ganjingzi District, Dalian, 116023 \\ Tel: 86-0411-84707346_E-mail: nancy623happy@yahoo.com.cn
}

Received: 06-09-2013

doi:10.7575/aiac.ijalel.v.3n.1p.79
Accepted: 14-10-2013

Published: 01-01-2014

URL: http://dx.doi.org/10.7575/aiac.ijalel.v.3n.1p.79

The research is financed by China's Fundamental Research Fund for Central Universities, (DUT12RW402).

\begin{abstract}
The improvement of women's social status has witnessed an increase of products and services specially designed for women and, therefore, an upsurge of related female advertisements. The extant studies mostly concentrate on the pragmatic analysis of advertising discourses and explore the implicit implications of gender and ideology in female advertisements. This research, by putting female advertising discourse in a commercial setting and case-studying the most sellable English fashion magazine, aims to figure out whether reason appeals or emotional appeals are more prevailing. Based on Halliday's System-Functional Linguistics, advertisement appeals are studied through examining the quantitative relationship of the occurrences of Material process and Mental process. The advertising data are collected from the women magazine COSMO, including 50 pieces of full-page advertisements about fashion and beauty in 2011 and 2012. Firstly, the Wordsmith tool extracts the verbs and calculates the frequency of verbs. The Material process to Mental ratio is 7 to 3, which basically supports that there are more reason appeals in English women advertisements. Then, every sample as well as its context is studied for Critical Discourse Analysis, and the results verify the conclusion that English women's advertisements employ more reason appeals. In light of the findings, recommendations are offered on how to build successful advertising discourses for women's products.
\end{abstract}

Keywords: Advertisement, Material process, Mental process, Critical Discourse Analysis

\section{Introduction}

In modern society, advertising has pervaded every corner of our daily life so that some people even believe that the air we breathe is made up of hydrogen, oxygen and advertising. Advertising language is the core part of advertisements, by which customers learn the information of commodity and services. A good piece of advertisement can help make successful persuasion. There are many advertisements considered peculiar to women, especially in fashion and beauty. With an enormous upsurge of interest in the studies of adverting discourses, there have been many researches on women advertising discourses.

Most of those studies and researches on this subject have been devoted to the major levels of language organization in advertisements, including phonology, graphology, lexis and syntax (Vestergaard and Schroder, 1985). Harris and Jackson (1983) mentioned its cognitive features in Information processing research in advertising. Aman (1982) analyzed the cultural and anthropological dimensions of advertising discourses. And similarly Anthony (1993) referred to the status of advertising as a genre or register of discourse. Working within the tradition of critical discourse analysis, 
Williamson (1978) explored the political and ideological significance of advertising discourse and, from this perspective, special attention had been paid to the representation of gender in advertisements.

Different from these referenced pragmatic explorations of advertising discourses, this study focuses on the appeals of advertising discourses. As early as in 1974, Bernste theoretically studied the strategies and goals of modern marketing in which a key binary distinction is drawn: "reason" advertising and "tickle" advertising. The "reason" advertising suggests a motive or reason for purchase and has more reason appeals, while the "tickle" advertising suggests humor, emotion and mood and has more emotional appeals. This topic is recently touched upon by Simpson (2001), who explored and established certain features of advertising discourse. The development of these criteria has led to the hope that advertisements' appeals can be systematically studied based on the linguistic criteria and related marketing recommendations can be made.

The present research combines qualitative and quantitative analyses in the study of the vocabulary of the most sellable women's magazines in order to examine whether women advertisements focus on "reason" appeals or on emotional appeals. Specifically, I investigate the most frequent vocabularies (mainly verbs) of the magazines by establishing two corpuses and analyze the quantitative relationship of the occurrences of material process and Mental process. The quantitative results offer insights used for a more detailed analysis in which I examine the ideological weight of specific words in their linguistic context.

\section{Methodology}

This research aims to find out what are women's appeals in English advertisements and, therefore, a large number of authentic language data are necessary. For this purpose, a corpus is built to show the numerical relationship of the two appeals. And the Transitivity of System-Functional Linguistics and Critical Discourse Analysis are employed for a further study of the corpus. The details are as follow:

\section{$2.1 \mathrm{Tool}$}

In the present study, Wordsmith (5.0) is employed as the main tool of analysis. Concord, Wordlist and Keyword are the core functions of the software. Concordance is built based on Concord. Concordance is a list of target words extracted from a given text, or a set of texts and is used to indicate the context where the word is used. Wordlist tool lists all the words that are different from the text corpus in an alphabetically or frequency order. Therefore it clearly shows the lexical similarities and differences of texts. It proves to be effective for the study.

\subsection{Data}

This study collects 50 pieces of full-page women advertisements from 2011 to 2012 about fashion and beauty from COSMOPOLITAN, short as COSMO. COSMO is one of the most popular women magazines, whose contents include interpersonal relationship, health, career, entertainment stars and fashion and beauty. The data collected focus on fashion and beauty, a topic women are most commonly concerned with. The length of texts varies from 2 to 106 , with a total of 1915 words.

\subsection{Research procedures}

Wordsmith is used to conduct quantitative analysis in this paper. The results can statistically show the relationship of verbs in women advertisements related to "reason" and "emotion". To deep into the context on the discourse level, the CDA (Critical Discourse Analysis) is applied. CDA, the most effective analysis tool, has been used in a variety of linguistics settings, among which transitivity has been discussed as an analysis tool. As a part of the ideational function of language in Halliday's System-Functional Linguistics, it deals with process types, participants and circumstances in the grammar of the clauses, which are the main three components in a process. There are six types of process: material process, mental process, relational process, behavioral process, verbal process and existential process (Halliday, 2000:107).

In the paper, the first two types of process are examined, because they can reflect, directly and clearly, the appeal types. Material process is a process of doing. It expresses the notion that some entity "does" something-which can be done to some other entity. The one that does the deed is called ACTOR and the other one that the deed is directed at is GOAL (Halliday, 2000:107). Verbs characterized by material process can be categorized as reason appeal, such as description of products.

The tablets also contain biotin, which is necessary for healthy hair growth, as well as copper, that may help maintain a normal pigmentation of the hair, preventing gray hair.

In contrast, Mental process is the process of sensing. The two participants in mental process are SENSER and PHENOMENON. The SENSER is the conscious being that is feeling, thinking and seeing. The PHONOMENON is that which is sensed-felt, thought and seen. It may be well defined as perception process (seeing, hearing and so on), affection process (liking, fearing and so on) and process of cognition (thinking, knowing, understanding and so on) (Halliday, 2000:107). Verbs of this quality belong to the emotion appeal, such as descriptions of feelings when customers use products.

\section{You'll look and feel awesome fast.}

Through the study of the quantitative relationship of the verbs that occur in the advertising discourse, the paper finds the quantitative relationship of Material process and Mental process, which is the key to figuring out the appeals of English 
women's advertisements. If the majority of verbs are of the Material process, then the persuasion uses more reasons, while if it's not, then persuasion uses more emotions.

\section{Data and Results}

\subsection{Data Analysis by Wordsmith}

According to the theory of transitivity, verbs are the core of the process from which process type and related appeal types can be judged. Thus Wordsmith tool firstly displays the frequency of verbs in the 50 samples as shown in Table 1 .

Table 1. The frequency of verbs

\begin{tabular}{l|l|l|l|l|l}
\hline Word (v.) & Freq. & $\%$ & Word (v.) & Freq. & $\%$ \\
\hline can & 14 & 0.61 & design & 3 & 0.13 \\
\hline wear & 11 & 0.48 & discover & 3 & 0.13 \\
\hline get & 10 & 0.43 & loss & 3 & 0.13 \\
\hline feel & 8 & 0.35 & made & 3 & 0.13 \\
\hline look & 8 & 0.35 & prove & 3 & 0.13 \\
\hline help & 6 & 0.26 & stop & 3 & 0.13 \\
\hline make & 6 & 0.26 & strength & 3 & 0.13 \\
\hline like & 5 & 0.22 & study & 3 & 0.13 \\
\hline have & 5 & 0.22 & take & 3 & 0.13 \\
\hline has & 5 & 0.22 & boost & 2 & 0.09 \\
\hline create & 5 & 0.22 & care & 2 & 0.09 \\
\hline fit & 4 & 0.17 & contain & 2 & 0.09 \\
\hline love & 4 & 0.17 & damage & 2 & 0.09 \\
\hline run & 4 & 0.17 & imagine & 2 & 0.09 \\
\hline stretch & 4 & 0.17 & protect & 2 & 0.09 \\
\hline clean & 3 & 0.13 & promise & 2 & 0.09 \\
\hline & & & stimulate & 2 & 0.09 \\
\hline
\end{tabular}

To study the quantitative relationship of verbs, we have to extract them and judge to which type of process they belong. If the verb expresses the notion that some entity "does" something which can also be "done" to some other entity, it is a process of doing. It is Material process. On the other hand, if the verb is a sense verb: feel (like, fear and so on), think (know, understand and so on) and see (see, hear and so on), it is a process of sensing. It is Mental process. A summary is shown in Table 2.

Table 2. Verb categorization and its frequency

\begin{tabular}{l|l|l}
\hline Types of process & Material process & Mental process \\
\hline The verbs occurred in the process & $\begin{array}{l}\text { wear, get, help, make, have, has, create, } \\
\text { run, strength, clean, design, discover, } \\
\text { made, stop, study, take, boost, contain, } \\
\text { damage, protect, stimulate }\end{array}$ & $\begin{array}{l}\text { feel, looke, fit, } \\
\text { imagine, promise }\end{array}$ \\
\hline The number of the tokens & 21 & 9 \\
\hline The percentage of the tokens & $70 \%$ & $30 \%$ \\
\hline The number of the occurrences & 87 & 36 \\
\hline The percentage of the occurrences & $70.73 \%$ & $29.27 \%$ \\
\hline
\end{tabular}

As shown in Table II, both in the percentage of tokens and in the percentage of occurrences, Material process accounts for about $70 \%$, being in the majority. It means that in the English women's advertisements, the application and frequency of Material process are more prevailing than those of Mental process. And from the results, it can be found that in the English women's advertisements, there are more occurrences of reason appeals than emotional appeals. However, there are some limitations in the application of Wordsmith. The accurate result of Wordsmith is based on a large number of corpora and some past participles, passive voices and -ing form of verbs cannot be detected only according to the frequency of verbs. What's more, Wordsmith only displays the occurrences of the verbs, unable to show their attribute, a notional verb or an auxiliary. Here are two examples.

There are a lot of things women would rather have on their minds than their pantiliner. So thin and absorbent. You'll forget you're wearing a liner. Wonderfully forgettable. (sample 2)

It's the most important thing you'll put on today. New. DayWear SPF 15. Now with the most effective anti-oxidant power ever. Anti-oxidants. What's good for your body can also be good for your skin. That's why it's important to wear 
DayWear. Our proprietary Super Anti-Oxidant Complex is so powerful, no anti-oxidant we have researched comes close-plus it defends against every key type of skin-aging free radical. This advanced moisturizer visibly diminishes first signs of aging like fine, dry lines and dullness. In fact, 96\% of women said their skin left smoother, fresher and healthier instantly. (sample 19)

Both in sample 2 and sample 19, the verb "have" occurs. The "have" in sample 2 is a notional verb, which means "have or possess, either in a concrete or an abstract sense". It is a Material process. While the "have" in sample 19 is an auxiliary, which doesn't make any sense in the process. It is neither Material process nor Mental process. Given the results that have been achieved and to make an accurate analysis, a further study is carried out that goes into the linguistic context of advertising discourse. The use of transitivity is explored under the framework of CDA.

\subsection{The Analysis of the Use of Transitivity}

Halliday said, "Material process is the process of external world, while Mental process represents the inner experience" (Halliday 2000: 107). The analysis of the data concerns the occurrences of the two main types of process in transitivity, Material process and Mental process. The detailed analysis is shown in Appendix 1 with the verbs in the Material process underlined with "__ and the verbs in the Mental process underlined with "_.". There are all together 198 occurrences of the two types of process, with 151 pieces of Material process and 47 pieces of Mental process.

Table 3. The occurrences of Material process and Mental process.

\begin{tabular}{l|l|l}
\hline Types of process & Material process & Mental process \\
\hline The number of occurrences & 151 & 47 \\
\hline The percentage of occurrences & $76.26 \%$ & $23.74 \%$ \\
\hline
\end{tabular}

Similarly, the result of Table III is very close to that of Table II: Material process holds a percentage of more than $70 \%$, taking up the majority of the advertising discourse. Unlike the result of Table II, the data in Table 3 is more accurate, in that it has analyzed every form of verbs in the samples: past participles, passive voices and -ing form and attribute of the verbs. Thus, this result verifies the finding that there are more reason appeals than emotional appeals in English women's advertisements. And to conduct a deeper analysis of the quantitative relationship of Material process and Mental process, these two types of process are classified into different categories according to their percentage.

As Table IV shows, there are four categories: i) the samples containing only Material process; ii) the samples containing Material process with more than $50 \%$; iii) the samples containing only Mental process; iv) the samples containing Mental process with more than $50 \%$.

Table 4. Classification of the 4 categories

\begin{tabular}{l|l|l|l}
\hline Classification of category & Number of occurrences & Percentage \\
\cline { 1 - 2 } Only Material process & 21 & $42 \%$ & \multirow{2}{*}{$78 \%$} \\
\cline { 1 - 2 } $\begin{array}{l}\text { Material process more than } \\
50 \%\end{array}$ & 18 & $36 \%$ & \\
\hline Only Mental process & 6 & $12 \%$ & $22 \%$ \\
\hline $\begin{array}{l}\text { Mental process more than } \\
50 \%\end{array}$ & 5 & $10 \%$ & \\
\hline
\end{tabular}

There are 21 samples containing only Material process in the 50 samples of English women advertisements in contrast with 5 samples containing Mental process. And the sum of samples in which Material process is in the majority is 39 , with a percentage of $78 \%$. These data are a solid support to the conclusion that reason appeals are more evident in the English women's advertisements.

In the analysis and collection of data, a phenomenon cannot be ignored that the number of words in the sample indicating Material process as the majority is larger than that of Mental process, as shown in Table 5.

Table 5. Word Number in samples

\begin{tabular}{l|l|l|l}
\hline $\begin{array}{l}\text { Number of words in a } \\
\text { sample }\end{array}$ & $\begin{array}{l}\text { Mental process in the } \\
\text { majority }\end{array}$ & $\begin{array}{l}\text { Material process } \\
\text { in the majority }\end{array}$ & $\begin{array}{l}\text { Proportion of Mental } \\
\text { process }\end{array}$ \\
\hline Less than 30 words & 9 & 16 & $36 \%$ \\
\hline $30-50$ words & 1 & 9 & $10 \%$ \\
\hline More than 50 words & 1 & 14 & $6.67 \%$ \\
\hline Largest number of words & 63 & 107 & \\
\hline
\end{tabular}

As can be seen, most of samples in which Mental process take up the majority are less than 30 words, while more than a half of the samples in which Material process is in the majority have more than 30 words. And the proportion of Mental 
process is getting smaller with the increase of words in a sample. When the number of the samples increases in the sample, Material process is more commonly used in the advertising discourse.

\section{Discussion}

\subsection{Implications of the dominance of Material process in English women's advertisements}

After the data analysis, we come to the conclusion that Material process is in the majority in English women's advertisements with a rough proportion of $70 \%$. Two reasons contribute to the phenomenon that women appeal more to reasons than to emotions in the English women's advertisements. Firstly, materiality is the essential attribute of the world. Material process is the main type of process that is used to describe the world and the matters. To attract the target buyers and persuade them to purchase the commodity, advertisers have to provide enough information about the products. Thus as the process of external world, Material process is the main tool to describe the products' appearance, shape, size, function, effect and so on. Secondly, it is a prejudice on women. According to Yu's Gender Ideology in Advertising Discourse-A Critical Discourse Analysis (2009), the proportion of Mental process in women's advertising discourses is bigger than that in man's an shown in Table 6.

Table 6. The number of the occurrences and percentage of the occurrences of Material process, Mental process and Relational process (Yu, 2009)

\begin{tabular}{l|l|l|l|l}
\hline $\begin{array}{l}\text { The number of the } \\
\text { occurrences/the percentage of } \\
\text { the occurrences }\end{array}$ & \multicolumn{2}{l}{ Men's advertising discourses } & \multicolumn{2}{l}{ Women's advertising discourses } \\
\hline Material process & 91 & $71.65 \%$ & 98 & $64.91 \%$ \\
\hline Mental process & 5 & $3.94 \%$ & 11 & $7.28 \%$ \\
\hline Relational process & 31 & $24.41 \%$ & 42 & $27.81 \%$ \\
\hline
\end{tabular}

As shown in Table VI, the percentage of Mental process in women's advertising discourses almost doubles that of man's. Women, compared with men, are thought to enjoy more emotional appeals than reason appeals. From a traditional point of view, advertisers tend to think that men are more independent and able to understand the logical description of products, while women care more about their inner experience and feelings, but are less independent and decisive. What's more, without a detailed analysis of the advertising discourse, the readers of advertisements cannot find this implicit rule and it has become what customers always take for granted. Therefore, this stereotypical thinking that there are more Material process in men's advertisements while more Mental process in women's advertisements might lead to the misunderstanding that women go after more emotional appeals.

\subsection{Strategies in English women's advertisements}

As Material process makes a proportion of as high as $70 \%$ of the occurrences of process in advertising discourses, the use of Material process plays an important part in advertising discourses. In addition, the female liberty movement led more and more women to have the chance of education as men. They have as much knowledge as men. Therefore, some strategies concerning Material process play important roles in advertising discourses.

\subsubsection{The use of figures}

The use of specific figures can make the description more accurate, scientific and convincing. Advertisements are designed to introduce the products and services so as to impress the customers so that they can decide to make purchases. The use of figures is very effective method in advertisements.

24 hour intensity. Tattoo tenacity. Dare to wear our longest-lasting shadow. Our ink technology creates supersaturated color. Cream gel smoothes on for vibrant color that does not fade. Dare to get inked. In 10 shades. (Sample 8)

Sample 8 is an advertisement of Maybelline cream gel. In this sample, there are two figures: "24" and " 10 ". There are 24 hours in a day, and " 24 hour intensity" shows that the effect of this cream gel can last all day, which is a very attractive promise for ladies. "10" is used to describe the effect of cream gel which can be as inked as 10 shades. The use of the two figures is impressive and gives an objective image of the products.

\subsubsection{The suitable collocation of Material process and Mental process}

As we have found that the proportion of Material process and Mental process in the English women's advertisements is $7: 3$, the producers of women's advertisements should take this number into consideration. The Material process describes the products' appearance, shape, size, function, effect and so on, while the Mental process pay attention to the inner experience and feelings of women. The collocation of these two kinds of process consists of both the reason appeal and emotional appeal, which is supposed to be more comprehensive and balanced such as the Sample 13 and Sample 27.

I had a bad fall and ended up with a large cut along my shin bone. I like to wear skirts and dresses so I was worried about having a scar in such a noticeable place. Just as the wound was healing, I read an article in a magazine in which a celebrity swore by Bio-Oil. I was skeptical, but I thought it was worth a try. I faithfully followed the directions for 
using Bio-Oil, and my scar is now less noticeable. I feel confident wearing skirts and dresses again, and I have Bio-Oil to thank. (Sample 13)

Feel it. Wear it. Love it. Discover the hold of a longwear in the luxury of a lipstick. Color that grabs hold of you and doesn't let go. (Sample 27)

\subsubsection{The illustrative list of facts and logical reasoning}

As a practical style of literature form, the facts are more important and authentic compared with the stack of rhetoric and marketing methods in advertising discourses. To make the facts logical, easy to understand and impressive is important for a good advertisement. An illustrative list of facts and logical reasoning can clearly display the use and effect of the product or service, which might as well make a successful persuasion of purchase. And Sample 16 is a good example.

The Hair Volume tablets are a new invention for hair. Hair Volume contains the special Procyanidin B-2 growth factor from apples- a natural ingredient that may stimulate the hair cells to grow. The tablets also contain biotin, which is necessary for healthy hair growth, as well as copper, that may help maintain a normal pigmentation of the hair, preventing gray hair. The tablets finally contain extracts of millet, silica and vitamin Bs, which increase hair growth and volume. (Sample 16)

There are four facts in the sample: i) special Procyanidin B-2 growth factor from apples $\rightarrow$ stimulate the hair cells to grow; ii) biotin $\rightarrow$ necessary for healthy hair growth; iii) copper $\rightarrow$ help maintain a normal pigmentation of the hair, preventing gray hair; iv) extracts of millet, silica and vitamin Bs $\rightarrow$ increase hair growth and volume. The list of facts clearly shows the customers the elements of the Hair Volume tablets: special Procyanidin B-2 growth factor from apples, biotin, copper and extracts of millet, silica and vitamin Bs and the effects of the product: stimulate the hair cells to grow, healthy hair growth, maintain a normal pigmentation of the hair, preventing gray hair and hair growth and volume. The list of elements and effects makes this advertisement very specific and impressive. The targeted customers who are in need of hair volume may easily remember this advertisement and get the information of the product. It is clear, easy to understand, impressive and attractive to the purchasers.

4.2.4 Contrastive study with the like products

It is a commonly used strategy in advertisements to make a contrastive study between the target product or service and the like products or service alike, which is also effective and practical. In the advertisements, advertisers display the strong points of the product or service through the contrast with the like one to impress and attract the target customers so as to make successful persuasions of purchases. Through the contrast, those famous brands with big market shares can show their advantages, while those emerging brands with small market shares can highlight their unique features to improve the product image.

Perfectly cut to reveal amazing brilliance, there's no better diamond than hearts on fire. And no better time to finally get one. (Sample 3)

Pro Clinical Hydroxycut is the latest weight loss innovation from the Hydroxycut brand, an established industry leader with a commitment to excellence that has stood for over 16 years. This powerful formula has a key ingredient combination clinically proven to help subjects lose more weight than dieting alone. In fact, where all groups followed a calorie- reduced diet, the average weight loss with the key ingredients was $20.94 \mathrm{lbs}$. vs. $1.70 \mathrm{lbs}$. with placebo in a 12 week study, and $16.50 \mathrm{lbs}$. vs. $1.73 \mathrm{lbs}$. in an 8-week study. (Sample 18)

In Sample 3, there is the comparative form "better". It gives the customers a message that the "hearts on fire" is the best diamond in the world and it is a right choice to buy it. This expression is positive and promotes the sales of products.

\section{Conclusion}

The paper aims to find out the appeals in English women's advertisements: more reason appeals or more emotion appeals under the framework of Corpus Linguistics and Critical Discourse Analysis. And the results of analysis indicate that the occurrences of Material process to Mental process ratio is approximately 7 to 3, which means that Material process is in the overwhelming majority. Therefore, a conclusion can be reached that in English women's advertisements there are more reason appeals than emotional appeals.

And as a practical style, advertising discourses aim to make the products or services more attractive and impressive so as to make persuasions of purchases. Some strategies are necessary, especially from the aspect of Material process.

1) The use of figures

The prior task of advertisements is to gain the trust and acceptance of the customers for the products or service so as to make a successful persuasion of purchase. And the use of specific figures can avoid too much use of the comparative and superlative forms of adjectives, which will improve the credibility of the products or service. It also can make the description more accurate, scientific and convincing. The use of figures is very effective method in modern women advertisements.

2) The suitable collocation of Material process and Mental process 
An appropriate proportion of Material process and Mental process can satisfy both the reason appeals and the emotional appeals of women in advertisements. And the collocation of the two types of process with the proportion of 7:3 proves to be comprehensive, effective and convincing.

3) The list of facts and logical reasoning

Compared with the stack of rhetoric and marketing methods, the most convincing part of an advertisement is about facts. The list of facts and logical reasoning makes the description of products or service logical, easy understanding and impressive, which is important for a good advertisement.

4) The contrast with the similar products

It is a commonly used strategy in advertisements to make a contrast between the target product or service and its alike products or service, which is very effective and practical. In the advertisements, the advertiser displays the strong points of the product or service through contrasting the item with the similar ones to impress and attract the target customers so as to make successful persuasion of purchase.

\section{References}

Aman, R. (1982). "Interlingual Taboos in Advertising: How Not to Name Your Product", in Pietro, R.J. Di, ed., Language and the professions, Norwood, NJ, Ablex, 215-224.

Anthony, B. (1993). "The Genre of Advertising". Revue Belge de Philologie et d'I-Iistoire 71,719-732.

Bernstein, D. 1974. Creative Advertising: For this You Went to Oxford?: a Personal Textbook of Advertising [M]. London: Longman.

Halliday, M. A. K., \& Webster J. (2009). The Essential Halliday [C]. Continuum International Publishing Group, London \& New York, 110.

Halliday, M. A. K. (2000). An Introduction to Functional Grammar. Foreign Language Teaching and Research Press, Beijing \& Edward Arnold (Publishers) Limited, London.

Harris, Richard Jackson, ed., (1983). Information Processing Research in Advertising. Hillsdale, NJ: Erlbaum.

Hunston, S. (2002). Corpora in Applied Linguistics. Cambridge University Press, Cambridge.

Simpson, P. (2001). 'Reason' and 'tickle' as pragmatic constructs in the discourse of advertising [J]. Journal of Pragmatics 33(4). pp: 589-607.

Vestergaard, T., \& Kim, S. (1985). The Language of Advertising, Blackwell, Oxford.

Williamson, J. (1978). Decoding Advertisements: Ideology and Meaning in Advertising. Marion Boyars, London.

Yu, J. (2009). Gender Ideology in Advertising Discourse-A Critical Discourse Analysis, master's dissertation, Fujian Normal University. 